\title{
DETERMINAÇÃO EXPERIMENTAL E MODELAGEM TERMODINÂMICA DE SISTEMAS DE DUAS FASES AQUOSAS COMPOSTO POR N-PROPANOL E SULFATO DE AMÔNIO APLICADO NA SEPARAÇÃO DO CORANTE AZUL BRILHANTE REMAZOL R
}

\author{
M. G. SANGLARD ${ }^{1}$, F. O. FARIAS ${ }^{1}$, F. B. S. HOBI ${ }^{1}$, L. IGARASHI-MAFRA ${ }^{1}$ e M. R. \\ MAFRA $^{1}$. \\ ${ }^{1}$ Universidade Federal do Paraná, Departamento de Engenharia Química \\ E-mail para contato: mgsanglard@gmail.com
}

\begin{abstract}
RESUMO - Os Sistemas de duas fases aquosas (SDFA) tem sido empregados na separação/purificação de diferentes moléculas em razão de sua fácil operação, baixo custo, além de excelente biocompatibilidade e biodegradabilidade. Neste trabalho, o SDFA empregando álcool de cadeia curta, n-propanol, e sulfato de amônio foi avaliado quanto ao seu comportamento de fases e na partição do corante Azul Brilhante Remazol R. Foram obtidas curva binodal e linhas de amarração do sistema a $25^{\circ} \mathrm{C}$. Os modelos NRTL e UNIQUAC foram utilizados para correlacionar os dados obtidos experimentalmente, sendo o NRTL melhor para representação do sistema, com desvio de $0,24 \%$. Observou-se que o corante particionou preferencialmente para a fase rica em. n-propanol, apresentando um alto coeficiente de partição (K > 32) e elevada eficiência de separação $(94,24 \%)$.
\end{abstract}

\section{INTRODUÇÃO}

Sistemas de extração líquido-líquido, que convencionalmente fazem uso de solventes orgânicos, são amplamente utilizados em diferentes setores industriais para purificação e recuperação de biomoléculas (Albertsson, 1986; Li et al., 2015). Os SDFA, os quais fazem parte dos sistemas de extração líquido-líquidos, são geralmente formados por soluções aquosas polímero-polímero, sal-sal ou ainda polímero-sal (Huddleston et al., 1996; Willauer et al., 2002). Com o intuito de melhorar as características dos SDFA, compostos como os líquidos iônicos, soluções salinas, solventes eutéticos e álcoois têm sido propostos como substituintes de uma das fases destes sistemas (Zeng et al., 2014; Li et al., 2015). SDFA formados por álcoois de cadeia curta têm sido amplamente estudados por formar sistemas de baixa viscosidade, boa seletividade, fácil operação e baixo custo (Li et al., 2015). Estes sistemas vêm sendo aplicados no particionamento de fármacos (Zhu et al., 2013), pigmentos vegetais (Liu et al., 2013), óleos essenciais (Li et al., 2016) e corantes (Borges et al., 2016), dentre outros.

Desta forma, este trabalho tem por objetivo avaliar experimentalmente e por meio da correlação com modelo termodinâmicos (NRTL e UNIQUAC) o comportamento de fases do SDFA composto por n-propanol + sulfato de amônio + água, a $25{ }^{\circ} \mathrm{C}$, bem como aplicar esse sistema na extração do corante Azul Brilhante de Remazol R. 


\section{MATERIAIS E MÉTODOS}

\subsection{Materiais}

Foram empregados n-propanol (Synth, SP, Brasil) e o sulfato de amônio (Neon, SP, Brasil) em grau analítico. Os reagentes empregados nos experimentos não passaram por processos de purificação. Foi utilizada água osmolisada em todos os experimentos.

\subsection{Métodos}

Curva binodal: Para a obtenção da curva binodal do sistema a $25{ }^{\circ} \mathrm{C}$ e pressão atmosférica (aproximadamente $91 \mathrm{kPa}$ ) foi utilizada a metodologia proposta por Kaul (2000). A solução aquosa de um dos componentes é adicionada gota a gota na solução do segundo componente da mistura até que se atinja o ponto de névoa, o que correspondente à formação da região bifásica. Em seguida era adicionado água para que o sistema retornasse à região monofásica. A massa adicionada de cada componente era quantificada gravimetricamente em balança analítica (AUX320, Shimadzu). Este procedimento era realizado dentro de uma célula encamisada conectada a um banho termostático para controle de temperatura. O procedimento foi repetido até que houvesse pontos suficientes para a caracterização da curva binodal.

Linhas de amarração: Foram escolhidos 6 pontos de composição global dentro da região bifásica do sistema, os quais foram devidamente pesados em tubos de centrífuga utilizando uma balança analítica (AUX320, Shimadzu). Na sequência, as amostras foram agitadas em agitador vortex (MX-S, Gomixer) e mantidas em banho termostático durante 24 horas para atingir o equilíbrio. Em seguida, a fase de topo era cuidadosamente separada e pesada (Sampaio et al., 2016). A quantificação da composição das fases em equilíbrio (linhas de amarração) seguiu o método gravimétrico definido por Merchuk et. al. (1998). O comprimento (CLA) e a inclinação (ILA) das linhas de amarração foram calculados através das Equações 1 e 2 respectivamente.

$$
C L A=\sqrt{\left(X_{\text {topo }}-X_{\text {base }}\right)^{2}-\left(Y_{\text {topo }}-Y_{\text {base }}\right)^{2}} \quad \text { (1) } \quad I L A=\frac{Y_{\text {topo }}-Y_{\text {base }}}{X_{\text {topo }}-X_{\text {base }}}
$$

Partição do corante Azul Brilhante de Remazol R: Foram escolhidos 3 pontos de composição global, correspondentes às linhas de amarração 2, 4 e 6 (Tabela 1). Estes sistemas foram preparados seguindo a mesma metodologia para obtenção das linhas de amarração, porém a água foi substituída por uma solução contendo $500 \mathrm{mg} \mathrm{L}^{-1}$ do corante estudado. Após atingir o equilíbrio, as fases foram devidamente separadas e a concentração de corante nas fases de topo e fundo foram quantificadas utilizando um espectrofotômetro UV-VIS (UV1800, Shimadzu) a $591 \mathrm{~nm}$, utilizando uma curva de calibração obtida previamente. O Coeficiente de partição bem como a eficiência da partição da fase de topo foram calculados através das Equações 3 e 4 .

$$
k=\frac{[C]_{\text {topo }}}{[C]_{\text {fundo }}}
$$

$$
E=\frac{[C]_{\text {topo }} \cdot V_{\text {topo }}}{[C]_{\text {fundo }} \cdot V_{\text {fundo }}+[C]_{\text {topo }} \cdot V_{\text {topo }}}
$$




\section{Congresso Brasileiro de Engenharia Química \\ em Iniciação Científica \\ UFSCar - São Carlos - SP \\ 16 a 19 de Julho de 2017}

CONGRESSO BRASILEIRO DE ENGENHARIA

\section{RESULTADOS E DISCUSSÃO}

A curva binodal, as linhas de amarração e o ajuste do modelo obtidos pelo método gravimétrico de Merchuk et al. (1998) do sistema composto por n-propanol + sulfato de amônio + água a $25{ }^{\circ} \mathrm{C}$ estão representados na Figura 1 . O modelo proposto por Merchuk et. al. (1998), utilizado para quantificação das fases de topo e fundo das linhas de amarração, apresentou bom ajuste à curva binodal obtida experimentalmente $\left(\mathrm{R}^{2}>0,99\right)$. As composições globais utilizadas para a construção das linhas de amarração (LA), a inclinação e comprimento de cada linha de amarração são apresentadas na Tabela 1.

Figura 1 - Equilíbrio líquido-líquido do sistema n-propanol $+\left(\mathrm{NH}_{4}\right)_{2} \mathrm{SO}_{4}+$ água obtido a 25

${ }^{\circ} \mathrm{C}$ : Curva binodal e linhas de amarração

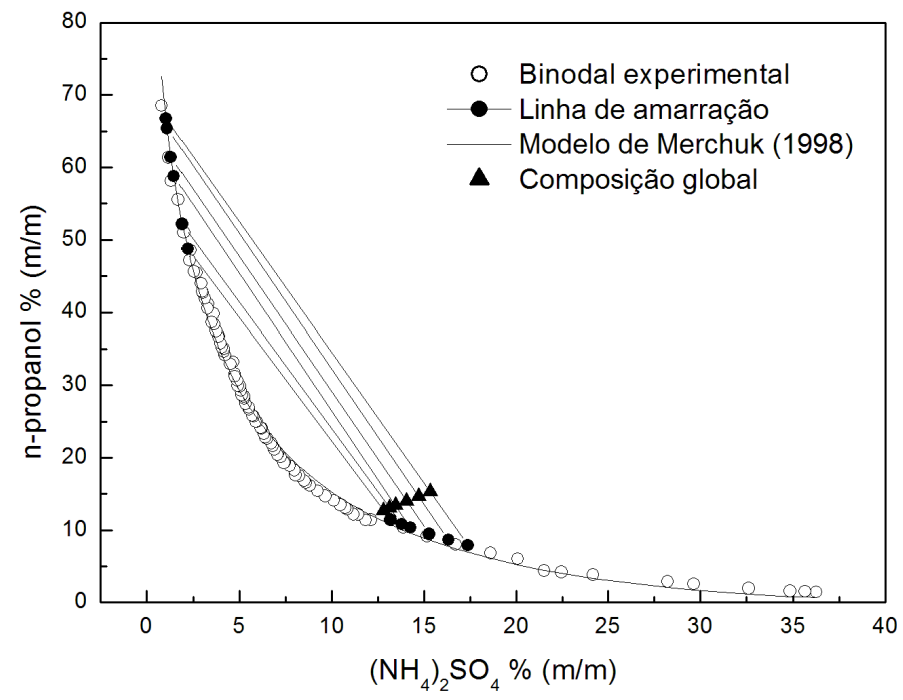

Tabela 1 - Dados de equilíbrio líquido-líquido do sistema n-propanol + $\left(\mathrm{NH}_{4}\right)_{2} \mathrm{SO}_{4}+$ água obtidos a $25^{\circ} \mathrm{C}^{\mathrm{a}}$

\begin{tabular}{|c|c|c|c|c|c|c|c|c|}
\hline \multirow{2}{*}{ LA } & \multicolumn{2}{|c|}{$\begin{array}{c}\text { Composição Global } \\
(\%, \mathrm{~m} / \mathrm{m})\end{array}$} & \multicolumn{2}{|c|}{$\begin{array}{c}\text { Composição de Topo } \\
(\%, \mathrm{~m} / \mathrm{m})\end{array}$} & \multicolumn{2}{c|}{$\begin{array}{c}\text { Composição de Fundo } \\
(\%, \mathrm{~m} / \mathrm{m})\end{array}$} & \multirow{2}{*}{ CLA } & \multirow{2}{*}{ ILA } \\
\cline { 2 - 6 } & $\mathrm{X}$ & $\mathrm{Y}$ & $\mathrm{X}$ & $\mathrm{Y}$ & $\mathrm{X}$ & $\mathrm{Y}$ & & \\
\hline \hline 1 & 12,82 & 12,72 & 1,91 & 52,42 & 13,17 & 11,45 & 42,48 & $-0,27$ \\
\hline 2 & 13,14 & 13,11 & 1,79 & 53,99 & 13,77 & 10,83 & 44,79 & $-0,28$ \\
\hline 3 & 13,46 & 13,45 & 1,47 & 58,77 & 14,28 & 10,34 & 50,09 & $-0,26$ \\
\hline 4 & 14,06 & 14,01 & 1,32 & 61,45 & 15,28 & 9,48 & 53,82 & $-0,27$ \\
\hline 5 & 14,71 & 14,72 & 1,11 & 65,41 & 16,34 & 8,66 & 58,76 & $-0,27$ \\
\hline 6 & 15,33 & 15,32 & 1,05 & 66,75 & 17,38 & 7,94 & 61,03 & $-0,28$ \\
\hline
\end{tabular}

${ }^{\mathrm{a}}$ Incertezas de medição (i): i(m) $=0,002 ; \mathrm{i}(\mathrm{T})=0,1^{\circ} \mathrm{C}$ e $\mathrm{i}(\mathrm{P})=10 \mathrm{kPa}$

Todas as linhas de amarração obtidas apresentaram aproximadamente a mesma inclinação (ILA médio de - 0,27) conforme pode ser observado na Tabela 1. 


\subsection{Modelagem termodinâmica}

Os parâmetros dos modelos NRTL e UNIQUAC foram estimados empregando o programa TML-LLE 2.0 desenvolvido por Stragevitch e D’Ávila (1997), o qual utiliza o princípio da máximo verossimilhança aliado a um algoritmo Simplex modificado para alcançar os pontos de mínimo global da função objetivo. Os parâmetros ajustados para os modelos NRTL e UNIQUAC para as linhas de amarração determinadas experimentalmente, são apresentados na Tabela 2.

Tabela 2 - Parâmetros estimados para os modelos NRTL e UNIQUAC do sistema n-propanol $+\left(\mathrm{NH}_{4}\right)_{2} \mathrm{SO}_{4}+$ água a $25^{\circ} \mathrm{C}$

\begin{tabular}{|c|c|c|c|c|c|c|c|}
\hline \multirow{2}{*}{$\mathrm{i} / \mathrm{j}$} & \multicolumn{4}{|c|}{ NRTL } & \multicolumn{3}{|c|}{ UNIQUAC } \\
\hline & $\mathrm{A}_{0, \mathrm{ij}}$ & $\mathrm{A}_{0, \mathrm{ji}}$ & $\alpha_{\mathrm{ii}}$ & $\operatorname{rmsd}^{\mathrm{a}}(\%)$ & $A_{0, i j}$ & $\mathrm{~A}_{0, \mathrm{ji}}$ & $\operatorname{rmsd}^{\mathrm{a}}(\%)$ \\
\hline n-propanol/( $\left(\mathrm{NH}_{4}\right)_{2} \mathrm{SO}_{4}$ & 1492,0 & 1414,6 & 0,23786 & \multirow{3}{*}{0,24} & $\begin{array}{l}-181,02 \\
\end{array}$ & 1694,7 & \multirow{3}{*}{1,59} \\
\hline n-propanol/água & 744,09 & 756,04 & 0,46235 & & $-186,42$ & 172,15 & \\
\hline$\left(\mathrm{NH}_{4}\right)_{2} \mathrm{SO}_{4} /$ água & $-1208,7$ & 3832,0 & 0,38432 & & $-869,61$ & 0,07725 & \\
\hline
\end{tabular}

${ }^{\mathrm{a}} \mathrm{rmsd}$ - root mean square deviation

Obteve-se desvios quadráticos médios de 0,24 \% para o modelo NRTL e de 1,59\% para o modelo UNIQUAC na representação do ELL do sistema n-propanol + $\left(\mathrm{NH}_{4}\right)_{2} \mathrm{SO}_{4}+$ água a $25^{\circ} \mathrm{C}$. Na Figura 2 pode-se observar que as linhas de amarração obtidas experimentalmente e aquelas preditas pelo modelo NRTL quase se sobrepõe completamente, indicando boa correlação, contudo as linhas preditas pelo modelo UNIQUAC apresentaram desvio considerável da realidade. Este comportamento era esperado, pois sistemas formados por álcoois estabelecem forças intermoleculares de força elevada (ligações de hidrogênio) que causam desvios incomuns na predição do modelo UNIQUAC (Prausnitz et al., 1999).

Figura 2 - Sistema n-propanol $+\left(\mathrm{NH}_{4}\right)_{2} \mathrm{SO}_{4}+$ água a $25^{\circ} \mathrm{C}$ : Linhas de amarração experimentais e preditas pelos modelos NRTL e UNIQUAC






\subsection{Partição do corante Azul Brilhante de Remazol R}

Os resultados para o coeficiente de partição (K) e eficiência da extração (E \%) do corante Azul Brilhante de Remazol R estão apresentados na Figura 3. As composições globais definidas para as linhas de amarração (LA2, LA4 e LA6) estão representadas na Tabela 1.

Figura 3 - Coeficiente de partição (K) e eficiência (E) do particionamento do Azul Brilhante Remazol R usando o sistema n-propanol $+\left(\mathrm{NH}_{4}\right)_{2} \mathrm{SO}_{4}+$ água a $25{ }^{\circ} \mathrm{C}$

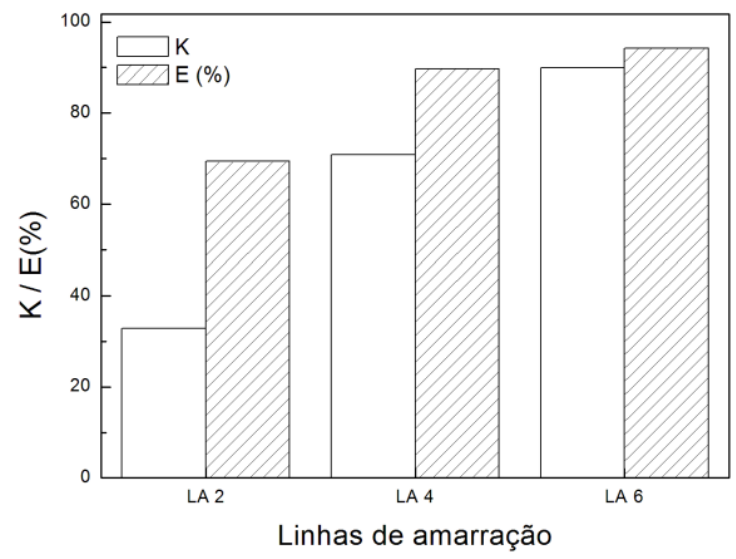

Para todos os ensaios obteve-se altos valores de coeficiente de partição $(K>32)$. Valores de K maiores que 1 indicam preferência do composto particionado pela fase de topo (rica em n-propanol). O corante azul de Remazol R, muito utilizado na indústria têxtil pode causar grande impacto ambiental quando descartado de maneira indevida (Zhengyu et al., 2016). Desta forma, a alta eficiência de extração, entre 69,22 e 94,24 \%, demonstram que esse sistema apresenta grande potencial para aplicação na remoção deste corante de água residuais.

\section{CONCLUSÃO}

Neste trabalho, o equilíbrio líquido-líquido do SDFA composto por n-propanol + sulfato de amônio foi avaliado experimentalmente a $25{ }^{\circ} \mathrm{C}$. O sistema apresenta uma grande região heterogênea, o que favorece a sua aplicação como sistema de separação. A modelagem termodinâmica realizada com o modelo NRTL apresentou melhores resultados que a obtida pelo modelo UNIQUAC, com desvios médios de 0,24 e 1,59\% respectivamente. O sistema estudado também apresentou boa capacidade de extração do corante Azul Brilhante Remazol $\mathrm{R}$, com rendimento máximo de extração de $94,24 \%$ e coeficiente de partição elevado (> 32). Os resultados obtidos neste trabalho demonstram o potencial do sistema avaliado no tratamento de efluentes das indústrias têxteis, sendo uma alternativa de baixo custo e ambientalmente segura.

\section{AGRADECIMENTOS}

Os autores agradecem a Fundação Araucária e a CAPES (Coordenação de Aperfeiçoamento de Pessoal de Nível Superior) pelo suporte financeiro. 


\section{REFERÊNCIAS}

ALBERTSSON, P.A. Partition of Cell Particles and Macromolecules, 3rd ed., Wiley, New York, 1986.

BORGES, G. A.; SILVA, L. P.; PENIDO, J. A.; LEMOS, L. R.; MAGESTE, A. B.; RODRIGUES, G. D., A method for dye extraction using an aqueous two-phase system: Effect of co-occurrence of contaminants in textile industry wastewater. Journal of Environmental Management. v. 183, p. 196 - 203, 2016.

HUDDLESTON, J.; ABELAIRA, J. C.; WANG, R.; LYDDIATT, A. Protein partition between the different phases comprising poly(ethylene glycol)-salt aqueous two-phase systems, hydrophobic interaction chromatography and precipitation: A generic description in terms of salting- out effects. Journal of Chromatography B: Biomedical Applications, v. 680, n. 1-2, p. 31-41, 1996.

KAUL, R.H. Aqueous Two-Phase Systems, Methods and Protocols. Humana Press, New Jersey, 2000.

LI, Y.; ZHAO, Y.; HUANG, R.; CUI, Q.; LU, X.; GUO, H. A thermodynamic study on the phase behaviour of ethanol and 2-propanol in aqueous ammonium sulphate/sodium sulphate solution. Journal of Molecular Liquids, v. 211, p. 924-933, 2015.

LI, H.; FENG, Z.; WAN, L.; HUANG, C.; ZHANG, T.; FANG, Y. (Liquid + liquid) equilibria of four alcohol-water systems containing 1,8 -cineole at $\mathrm{T}=298.15 \mathrm{~K}$. J.Chem. Thermodynamics. v. 101, p. 387-394, 2016.

LIU, X.; MU, T.; SUN, H.; ZHANG, M.; CHEN, J. Optimisation of aqueous two-phase extraction of anthocyanins from purple sweet potatoes by response surface methodology. Food Chem, v. 141 p. 3034-3041, 2013.

MERCHUK, B.A.; ANDREWS, J.A.; ASENJO, J. Aqueous two-phase systems for protein separation: Studies on phase inversion. Journal of Chromatography B. v. 711, p. 285293, 1998.

PRAUSNITZ, J. M. et al. Molecular Thermodynamics of fluid phase-equilibria. 3rd ed. Prentice Hall PTR, New Jersey, 1999.

SAMPAIO, D.A., SOSA, F. H. B., MARTINS, A. D., IGARASHI-MAFRA, L. YAMAMOTO, C. I., SOUZA, M. O., CASTILHOS, F., MAFRA, M. R. Assessment of Sodium Salt Anions $\left(\mathrm{SO}_{4}{ }^{2-}\right.$ and $\left.\mathrm{NO}_{3}{ }^{-}\right)$Influence on Caffeine Partitioning in Polyethylene Glycol and 1-Butyl-3-Methylimidazolium Tetrafluoroborate Based ATPS, J. Solution Chem. v. 45, p. 1857-1878, 2016.

STRAGEVITCH, L.; D’ÁVILA, S. G. Application of a generalized maximum likelihood method in the reduction of multicomponent liquid-liquid equilibrium data. Brazilian journal of chemical engineering. v 6, n .3, p.252 - 263, 1997.

WILLAUER, H. D.; HUDDLESTON, J. G.; ROGERS, R. D. Solute Partitioning in Aqueous Biphasic Systems Composed of Polyethylene Glycol and Salt: The Partitioning of Small Neutral Organic Species. Industrial \& Engineering Chemistry Research, v. 41, p. 18921904, 2002.

ZENG, Q.; WANG, Y.; HUANG, Y.; et al. Deep eutectic solvents as novel extraction media for protein partitioning. The Analyst, v. 139, n. 10, p. 2565-73, 2014.

ZHENGYU, S. et al. Decolorization of Remazol Brilliant Blue $\mathrm{R}$ using a novel acyltransferase-ISCO (in situ chemical oxidation) coupled system. Biochemical Engineering Journal, v. 115, p. 56-63, 2016.

ZHU, H.; DING, Y.; JIA, Y. Hesperidin extraction from orange peel with new aqueous twophase system. J. Food Sci. Biotechnol, v. 32, n. 9, p. 995-1001, 2013. 